\title{
Research on Planning and Design of Urban Architectural Color in Changchun
}

\author{
Zhang Cui \\ Changchun Institute of Technology, 130021 Changchun, Jilin Province, P.R. China
}

\begin{abstract}
Architecture is the soul of city color. The planning focus of city color is city architecture, especially the planning control of the main wall color of street buildings. The design of architectural color should not only consider the surrounding environment of the building, the content of the building and the building materials, but also proceed from the aesthetic needs and conform to the principle of color engineering. On this basis, the plan proposes color design guidelines and relies on scientific and standardized "urban building color design guidelines" to achieve the purpose of maintaining the original appearance of history and creating a new era style. Besides the traditional buildings, the other "architectural color guidelines" should leave more room for manoeuvre and not restrict the creative thinking of architects.
\end{abstract}

\section{Introduction}

Changchun is not only the capital city of Jilin province, but also one of the central cities in northeast China. Although its cold climate has brought many negative impacts on urban development and residents' lives, this feature also gives it the connotation and significance different from other urban color designs. At present, the pollution of architectural color in Changchun is serious, and the main color of the city has not been determined. Buildings are the main body of the city, which can best reflect the color of the city. Changchun's natural conditions, socio-economic characteristics and cultural and historical evolution provide a broad background for urban color determination and construction.

\section{Design background}

\subsection{Natural environment}

Changchun belongs to a cold city in high latitude. Winter environment in cold cities is monotonous and dreary, vegetation withers, and the city is shrouded in grey without color. Generally, it is not suitable to use achromatic color system. Therefore, using a warm and comfortable color system can establish a rich and coordinated city color system. Changchun has a large amount of snow, and it snows a lot in winter. Therefore, the reflectivity of new snow to light is extremely high, reaching $95 \%$. In order to reduce the dazzling feeling of snow thickness, high-quality and high-purity colors should be avoided as the basic colors of the city, so slightly dark and warm colors are easier to achieve color balance.

\subsection{City size}

Changchun city covers an area of 3616 square kilometers with an actual resident population of more than 2 million, which is a large and medium-sized city. Large and medium-sized cities should adopt a zoning method in their tone color planning and pay attention to the coordination of the color atmosphere of the whole city. City buildings are the main body of the city, and their colors often form the basic tone of the city.

Starting from the local materials of the city, some Japanese-style buildings built during the Japanese invasion of China in changchun has formed a city color style with the characteristics of the times. Changchun now has many pseudo-manchurian buildings. So the exterior facade of buildings is mostly dark gray, maroon and yellow. The traditional colors should be preserved and continued.

\subsection{Endothermic nature of color}

Various colors absorb heat in different degrees under the action of solar radiant heat, which is related to the light and shade of material colors and also affects the choice of city colors. Changchun is often covered with snow all over the city in winter, and the reflection of snow is very strong, so the exterior facade color of Changchun buildings should not be too deep or too thick.

\subsection{Determination of city main color}

According to the characteristics of Changchun city, this study initially believes that Changchun city color planning should be based on the principle of "sprightliness, generosity, warmth and harmony" in order 
to create a colorful Changchun. The overall color of the city emphasizes the warm tone as the main tone, with slightly dark maroon and khaki as the main color of the city. The hue with lightness between N2 and N8 is more than one color, but all kinds of colors can be basically used. However, the overall hue is gray to maroon or khaki. On this basis, the hue, lightness and purity of the changed colors are adjusted to obtain auxiliary colors and embellishments, forming rich and harmonious city colors.

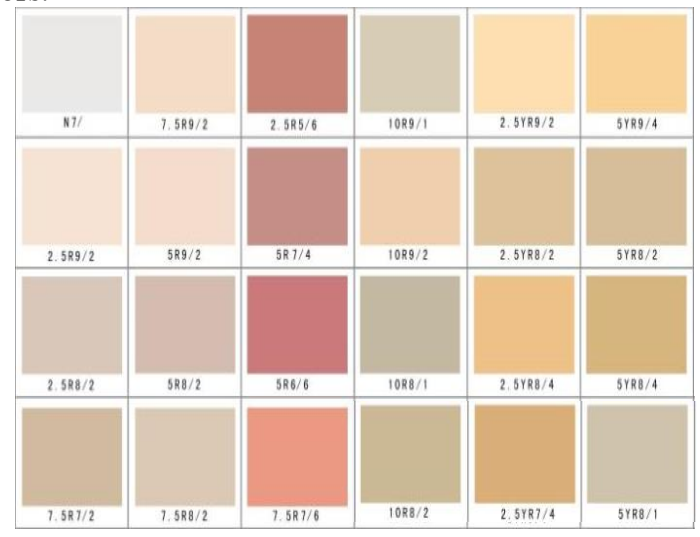

Fig. 1. Recommended chromatogram of main wall decoration of key buildings in Changchun

\section{Design suggestions}

The color design of the building can be guided and controlled according to the relevant guidelines for wall surface, roof, window decoration, balcony, line foot, glass and other parts. The tone color of large area (wall surface) should be mainly low purity color, such as slightly dark reddish brown, milk yellow and yellow-white warm tones; On this basis, the hue, lightness and purity of the changed colors are adjusted to obtain the colors of the roof and the lower wall. Bright colors can be used locally (window decorations, balconies, wire legs, glass, etc.). Through the scientific and standardized "color design guide for urban buildings", it can not only maintain the original appearance of history, but also create a new era style, with emphasis on planning and controlling the color of the main wall surface of buildings facing the street. From Changchun Railway Station to renmin street of Shengli Park, the facades and shop signs on both sides of the building have been designed with some systematic color planning, which can achieve harmonious and unified good visual effects, reduce the chaotic imagination of color, and establish the image of Changchun. Therefore, other buildings also need overall planning.

\subsection{Suggestions on color of office buildings}

It is suggested that the buildings in the administrative center area should be made of stone and brick materials to show the sedate and restrained city style and features of this section with a sense of architectural heaviness. Color selection is based on high brightness grayish white and slightly dark reddish brown. The auxiliary color can be low lightness, low chroma khaki and milky white, which are opposite to the basic color.

It is suggested that the administrative office buildings on both sides of the road in the public living area should be made of stone and brick materials, and the colors should be high-quality grayish white, high-quality and low-color maroon. The auxiliary color is selected as low lightness, low chroma khaki and maroon. It is suggested that the administrative office buildings on both sides of the road in the business district should be made of stone materials, and the colors should be medium-high color and medium-low color maroon. The auxiliary color is selected as low lightness, low chroma khaki and maroon. Administrative buildings on both sides of roads in high-tech district shall be made of glass curtain wall materials, and the colors shall be high-quality gray-white and high-quality low-color maroon. The auxiliary color should be medium-high color, medium-low color, maroon and khaki, which are similar to the basic color.

\subsection{Guidelines for controlling the main color of residential buildings}

It is suggested that coatings and brick materials can be used for residential buildings in commercial centers. The color selection should take low lightness and medium-high chroma maroon as the basic color. The matching of basic color and auxiliary color should adopt horizontal composition.

It is suggested that residential buildings on both sides of roads in public living areas should be made of brick materials. The colors should be medium-high gray and high-high and low-color maroon as the basic color, and the matching of basic color and auxiliary color should adopt vertical composition. The residential buildings on both sides of the roads in the old city should be made of brick and paint materials. The color should be medium-high brightness and medium-low color maroon as the basic color, and the matching of basic color and auxiliary color should be horizontal composition.

It is suggested that the residential buildings on both sides of the roads in the old city should be made of brick and paint materials, and the color should be maroon with low lightness and medium to high chroma, and the basic color and auxiliary color should be matched with horizontal composition. The residential buildings on both sides of the road in the business district should be made of brick materials. The color should be high-quality and low-color maroon as the main color, and the matching of the basic color and auxiliary color should be vertical composition.

It is suggested that brick materials should be selected for residential buildings in high-tech zones. The colors should be high-brightness, low-color light gray and maroon as the basic colors, and the matching of basic colors and auxiliary colors should be vertical composition. 


\subsection{Color suggestions for commercial entertainment buildings}

It is suggested that brick, paint, metal plate, glass and other materials should be selected for commercial and entertainment buildings in the commercial center area. The main color of the building should be chosen as the basic color of the building, and the color of glass should be colorless and light blue based on coordination with the regional environment.

It is suggested that the main wall surfaces of commercial and entertainment buildings on both sides of roads in public living areas should be made of brick, metal plate and glass materials. The colors should be high-quality and low-color maroon, and the glass should be colorless, light blue and dark brown. The commercial and entertainment buildings on both sides of the roads in the old city area are made of brick and metal plate materials, and the color selection is medium-high color and medium-low color maroon. Color, tan.

It is suggested that commercial and entertainment buildings on both sides of the roads in the old city should be made of brick and metal plate materials, and the colors should be of low brightness and moderate to high chroma maroon. Bricks, metal plates and glass materials are selected for commercial and entertainment buildings on both sides of the roads in the business district. The color selection is high-quality and low-color ochre as the basic color. Colorless, light blue and dark brown glass should be selected.

\subsection{Control guidelines for color planning of industrial buildings}

It is suggested that the building materials should be metal plates, stone and glass, with medium-high brightness and low chroma maroon close to achromatic color system as the basic color of the building, and medium-low brightness khaki and maroon as the auxiliary colors of the building, so as to enrich the color matching effect of the building. Glass using should not be formed into large-area glass curtain wall, and its color should be colorless and brown glass.

\subsection{Guidelines for controlling the main color of cultural, educational and health buildings}

It is suggested that cultural and educational buildings in the old city should use medium-low chroma and medium-low lightness maroon as the basic colors of buildings, and the auxiliary colors should use medium-high chroma, medium-high chroma khaki and ochre, which are the same as or similar to the basic colors, while those buildings with strong liveliness can use high chroma colors coordinated with the basic colors as the decorative colors.

It is suggested that the sanitary buildings in the old city should use medium-low chroma and medium-low lightness ochre as the basic color of the building, and the auxiliary color should be high chroma, low chroma milky white, maroon and colorless grayish white with the same hue as the basic color, which should form a quiet color combination.

It is suggested that cultural and educational buildings in the new city should use high-quality and low-color ochre as the basic color of buildings, the auxiliary color should use the same or similar hue as the basic color, and the high-color color coordinated with the basic color can be used as the decorative color for buildings with strong liveliness.

It is suggested that sanitary buildings in the new urban area should use high-gloss and low-color maroon as the basic color of the building, and the auxiliary color should be colorless gray white, medium-gloss and low-color khaki.

\subsection{Guidelines for color planning and control of large public buildings in urban areas}

Color tone color should be consistent with the surrounding environment, appropriate USES low chroma, high color. In order to better coordinate with the surrounding environment, the tone color of the building is grayish white close to the achromatic color system.

It can appropriately add high-color colors conforming to its functions to increase the sense of creative design of buildings according to different architectural functions,. High color milky white and maroon can be used as auxiliary colors to break the monotonicity of architectural colors.

Auxiliary color can be color with strong contrast with the basic tone color, which can be hue contrast or lightness contrast. Other colors with small area and high chroma can be used as decorative colors to increase architectural fashion sense.

\subsection{Principle of color application on building roof}

The roof color should be coordinated and unified among different building groups in adjacent areas. The planning suggests that the new urban area should have flat roof, and the old urban area should be partly reconstructed and adopt slope roof in combination with the surrounding buildings. When the roof is used on the top of the building, the color of the roof is one of the main colors of the building.

When flat roofs are used, consider creating a roof garden on the roof of some large public or residential buildings and decorating the roof with natural Chloroplastida.

The roof color should choose high color, low brightness red, dark gray tile color, and the surrounding natural environment, prohibit the selection of high brightness, high color.

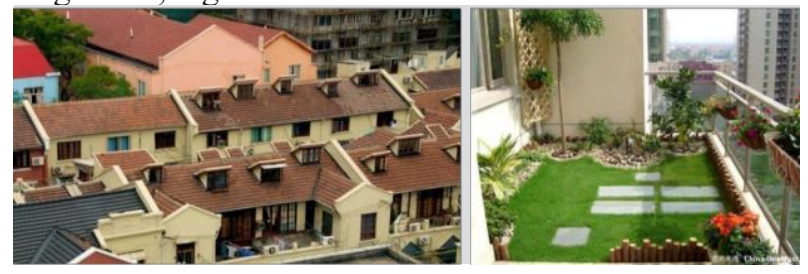

Fig. 2. Color scheme of roof 


\section{Summary}

The design of urban architectural color that we are going to carry out is aimed at "control", because we hope to obtain the overall grasp of urban color while preventing the occurrence of disharmonious color that damages the environment or the messy situation that each does its own thing and does not cooperate with each other. At the same time, the design should leave enough space for designers to achieve a harmonious and unified effect under the guidance of the overall color design principles, Therefore, only under the guidance of legal norms, supervision and guidance can the study embark on the road of standardization.

\section{References}

1. Jiang Honglang, Research on Quantitative Control Method of Urban Color Dominant Tone Based on Digital Technology-Taking Ankang City Color Planning and Design as an Example [Dissertation] (Chongqing University, 2013)

2. Zhang Yongming, Principles and Significance of Personalized Urban Color Planning and Design (Theoretical Research on Urban Construction (Electronic Edition), 2011)

3. Chang Li, On the Significance and Principles of Urban Color Planning (Theoretical Research on Urban Construction (Electronic Edition), 2013)

4. Donald A.Norman, The Design of Everyday Things (Beijing:City Publishing House, 2003)

5. Donald A.Norman, Emotional Desing (Beijing:City Publishing House, 2005) 